\title{
The cow pedogram-Analysis of gait cycle variables allows the detection of lameness and foot pathologies
}

\author{
M. Alsaaod, ${ }^{* 1}$ M. Luternauer, ${ }^{*}$ T. Hausegger, $†$ R. Kredel, $\dagger$ and A. Steiner* \\ *Clinic for Ruminants, Vetsuisse-Faculty, and \\ †Institute of Sport Science, Faculty of Human Sciences, University of Bern, 3001 Bern, Switzerland
}

\begin{abstract}
Changes in gait characteristics are important indicators in assessing the health and welfare of cattle. The aim of this study was to detect unilateral hind limb lameness and foot pathologies in dairy cows using 2 high-frequency accelerometers $(400 \mathrm{~Hz})$. The extracted gait cycle variables included temporal events (kinematic outcome $=$ gait cycle, stance phase, and swing phase duration) and several peaks (kinetic outcome $=$ foot load, toe-off). The study consisted of 2 independent experiments. Experiment 1 was carried out to compare the pedogram variables between the lateral claw and respective metatarsus (MT; $\mathrm{n}=12$ ) in sound cows (numerical rating system $<3, \mathrm{n}=12$ ) and the differences of pedogram variables across limbs within cows between lame cows (numerical rating system $\geq 3$, $\mathrm{n}=5)$ and sound cows $(\mathrm{n}=12)$ using pedogram data that were visually compared with the synchronized cinematographic data. Experiment 2 was carried out to determine the differences across limbs within cows between cows with foot lesions $(\mathrm{n}=12)$ and without foot lesions $(\mathrm{n}=12)$ using only pedogram data. A receiver operator characteristic analysis was used to determine the performance of selected pedogram variables at the cow level. The pedogram of the lateral claw of sound cows revealed similarities of temporal events (gait cycle duration, stance and swing phases) but higher peaks (toe-off and foot load) as compared with the pedogram of the respective MT. In both experiments, comparison of the values between groups showed significantly higher values in lame cows and cows with foot lesions for all gait cycle variables. The optimal cutoff value of the relative stance phase duration for identifying lame cows was $14.79 \%$ and for cows with foot lesions was $2.53 \%$ with (both $100 \%$ sensitivity and $100 \%$ specific-
\end{abstract}

Received June 29, 2016.

Accepted October 11, 2016

${ }^{1}$ Corresponding author: maher.alsaaod@vetsuisse.unibe.ch ity) in experiments 1 and 2, respectively. The use of accelerometers with a high sampling rate $(400 \mathrm{~Hz})$ at the level of the MT is a promising tool to indirectly measure the kinematic variables of the lateral claw and to detect unilateral hind limb lameness and hind limb pathologies in dairy cows and is highly accurate.

Key words: dairy cows, gait cycle, accelerometer, lameness

\section{INTRODUCTION}

Lameness and foot pathologies in cattle are among the most important welfare problems and are responsible for significant economic losses in the dairy industry (Bicalho et al., 2008; Schearer et al., 2013); lameness in cattle is an expression of pain. The etiologies and pathogeneses of some foot disorders are still relatively poorly understood (Huxley, 2012). Early lameness detection and prompt treatment reduce the duration and prevalence of lameness and thus improve cow welfare (Leach et al., 2012; Thomas et al., 2016). Change in an animal's behavior is one of the most important criteria in assessing animal welfare and health. For example, pain associated with claw or limb disorders causes alterations in gait characteristics and a decreased daily overall activity level (Thorup et al., 2014; Nechanitzky et al., 2016; Beer et al., 2016). The current gold standard for the detection of lameness in dairy cows is the clinical observation by a trained professional. The degree of lameness is described using a validated clinical gait-scoring system (Sprecher et al., 1997; Flower and Weary, 2006), this being a subjective method for assessing lameness. However, locomotion scoring requires observer training and may not be sensitive enough to detect slight gait alterations (Engel et al., 2003; Tadich et al., 2010). The difficulties in evaluating the stride and postural characteristics as well as the reproducibility of scoring mildly lame cows are most challenging (Engel et al., 2003; Holzhauer et al., 2005; Flower and Weary, 2006). In addition, cows showing impaired locomotion may not always express all traits described by 
a certain locomotion-scoring method (Schlageter-Tello et al., 2015). Automated and objective methods of lameness detection are an attempt to mimic locomotion scoring by measuring different traits using different types of sensors (Alsaaod et al., 2012; Van Hertem et al., 2014; Beer et al., 2016). Consequently, methods that objectively analyze cattle locomotion could provide useful information for (1) early and more accurate lameness detection, (2) early foot pathology detection, (3) improved intra- and interobserver agreement of gait scoring, (4) monitoring the effect of treatment strategies, and (5) assessing the influence of environmental conditions on locomotion.

The objective measurement of gait patterns in research studies is mainly based on 2 methods: (1) kinematic (changes in the position of the body segments during a specified time) gait analysis (Flower et al., 2005), such as high-speed cinematography with the cow on a treadmill (Schmid et al., 2009), image-processing techniques (Poursaberi et al., 2010; Viazzi et al., 2013), or accelerometers (Pastell et al., 2009; Alsaaod et al., 2015); and (2) kinetic (force applied to the body) gait analysis using 1- or 3-dimensional ground reaction force systems (Rajkondawar et al., 2006; Walker et al., 2010; Thorup et al., 2014) or pressure-sensitive walkways (Van Nuffel et al., 2009; Maertens et al., 2011). One of the drawbacks of some of these methods is that they are expensive or difficult to apply in clinical settings. Furthermore, data acquired from the use of highfrequency accelerometers to detect and characterize gait cycle patterns (such as characteristics of swing and stance phases) in cattle is still not available. To date, these sensors are partially used in equine medicine (Olsen et al., 2012) and for a broad range of applications in human movement science, sport science, and rehabilitation medicine (e.g., Lee et al., 2010; Mariani et al., 2013; Lugade et al., 2014). In human movement science, quantitative analysis of temporal events using inertial measurement units (IMU) provided a promising tool to assess normal and pathological ambulatory gaits. Consequently, investigating the gait cycle, as proposed in human movement research, might improve lameness detection in cattle movement research. The aim of our study was to determine whether measurements from accelerometers with high frequency (400 $\mathrm{Hz}$ ) would allow us (1) to describe the gait pattern of nonlame cows while walking, (2) to compare the acceleration between lateral claw and metatarsus (MT) of the same limb, (3) to determine the differences between hind limbs in nonlame and lame cows, and, finally, (4) to estimate the differences between both hind limbs in cows with unilateral foot pathologies as compared with cows without foot lesions.

\section{MATERIALS AND METHODS}

\section{Ethics Statement}

The study protocol was approved by the animal experimentation committee of the canton of Bern, Switzerland (permission \# 25601).

\section{Animals and Experimental Procedures}

The study consisted of 2 independent experiments, both carried out at the Clinic for Ruminants, VetsuisseFaculty, University of Bern. The cows of both experiments were submitted to a thorough orthopedic, radiographic, or ultrasonographic examination, if indicated (Dirksen et al., 2012). In experiment 1, 5 cows [group lame (L1)] that had been referred to the clinic for evaluation of a lameness problem in the area of the hind limbs and 12 dairy cows without any signs of lameness [group nonlame (C1)] were used. The lame group included cows with one of each of the following unilateral pathologies: bulb abscess, double sole, osteitis of P3, septic tendovaginitis of the common digital flexor tendon sheath, or septic arthritis of the tibiotarsal joint. In group $\mathrm{C} 1$, the mean $( \pm \mathrm{SD})$ lactation number was 2.58 $( \pm 1.31)$ with a mean daily milk yield of $30.5( \pm 8.87) \mathrm{kg}$ and a mean BW of $632.36( \pm 94.01) \mathrm{kg}$. The breeds involved were Holstein-Friesian $(\mathrm{n}=2)$, Red Holstein ( $\mathrm{n}$ $=4)$, Swiss Fleckvieh $(\mathrm{n}=5)$, and Rhätisches Grauvieh $(\mathrm{n}=1)$. In group L1, the mean lactation number was 1.2 $( \pm 0.45)$ with a mean daily milk yield of $25.5 \mathrm{~kg}( \pm 3.32)$ and a mean BW of $546.75( \pm 77.95) \mathrm{kg}$. The breeds involved were Holstein-Friesian $(\mathrm{n}=2)$, Red Holstein $(\mathrm{n}=1)$, Brown Swiss $(\mathrm{n}=1)$, and Eringer $(\mathrm{n}=1)$. In experiment 2, 12 dairy cows with no signs of orthopedic pathologies [no lesion group (C2)] and 12 dairy cows with unilateral claw pathologies [lesion group (L2)] were included. The lesion group included cows with the following pathologies [double sole $(\mathrm{n}=1)$, osteitis of $\mathrm{P} 3$ $(\mathrm{n}=3)$, fracture of P3 $(\mathrm{n}=2)$, Rusterholz ulcer $(\mathrm{n}=$ 1), septic arthritis of the distal interphalangeal joint (n $=1$ ), claw horn fissure $(\mathrm{n}=1)$, interdigital phlegmon $(\mathrm{n}=1)$, and white-line abscess $(\mathrm{n}=2)]$. In group C2, the mean $( \pm \mathrm{SD})$ lactation of the cows was $4.08( \pm 2.71)$ with a mean daily milk yield of $24.22 \mathrm{~kg}( \pm 6.65)$ and a mean BW of $660.83 \mathrm{~kg}( \pm 84.36)$. The breeds involved were Holstein-Friesian $(\mathrm{n}=4)$, Red Holstein $(\mathrm{n}=1)$, Swiss Fleckvieh $(\mathrm{n}=4)$, Simmental $(\mathrm{n}=1)$, Rhätisches Grauvieh $(\mathrm{n}=1)$, and Montbéliard $(\mathrm{n}=1)$. In group L2, the mean lactation of the cows was $2.67( \pm 2.35)$ with a mean daily milk yield of $25.54( \pm 7.05) \mathrm{kg}$ and a mean BW of $648.75( \pm 114.57) \mathrm{kg}$. The breeds involved were Holstein-Friesian $(\mathrm{n}=4)$, Swiss Fleckvieh $(\mathrm{n}=3)$, 
Simmental $(\mathrm{n}=2)$, Brown Swiss $(\mathrm{n}=1)$, and Eringer $(\mathrm{n}=2)$.

\section{Clinical Gait Score Assessment}

All cows were videotaped using a digital video camera (50 frames/s; Sony HDR-PJ740VE, Sony Corporation, Tokyo, Japan) to record the locomotion while the respective cow was walking on an asphalt floor in a straight line for $20 \mathrm{~m}$. The video recordings were blinded as to group allocation and pathology, and locomotion was scored using a 1 to 5 numerical rating system (NRS) with 0.5 -point increments (where $1=$ nonlame and $5=$ severely lame) based on 6 specific gait attributes (back arch, head bob, tracking up, joint flexion, asymmetric steps, and reluctance to bear weight; Flower and Weary, 2006). To maximize the reliability of clinical locomotion scoring, the mean value of 3 trained independent veterinary specialists was calculated and used for further analysis. Cows with a mean NRS $\geq 3$ were classified as lame.

\section{Measurement of Gait Kinematics}

In both experiments, gait kinematics were recorded after cows had been trained to walk appropriately. They were encouraged by a trained animal caretaker to walk in a straight line for a distance of $\geq 10 \mathrm{~m}$ on an asphalt floor (one walking phase) guided with a halter. To record this, (1) a gait analysis system designed for use in humans $(1,000 \mathrm{~Hz}$; Myon AG, Schwarzenburg, Switzerland) and (2) stand-alone accelerometers (400 $\mathrm{Hz}$; USB Accelerometer X16-4; Gulf Coast Data Concept, Waveland, MS) were used. The gait analysis system is comprised of 2 IMU (each including a 3-dimensional accelerometer, a 3-dimensional gyroscope, and a magnetometer, of which only the accelerometer data were used in this study) and a high-speed video camera $(120 \mathrm{~Hz})$. Cinematographic data and IMU were synchronized, allowing for concurrent analysis of accelerometer and cinematographic data.

\section{Experiment 1}

Part A of experiment 1 was performed to first analyze acceleration at the level of the lateral claw $\left(\mathrm{IMU}_{\text {claw }}\right)$ in comparison with the acceleration at the level of the metatarsus ( $\mathrm{IMU}_{\mathrm{MT}}$ and stand-alone accelerometer) of 1 randomly selected hind limb in cows of group C1. Second, we identified how the stance and the swing phase of the gait cycle (upon visually analyzing the cinematographic data) were expressed in the accelerograms of the claw and the MT, respectively. Simultaneously, characteristic peaks of the accelerograms were defined that represented the relevant aspects of the gait cycle and were easily identified by visual inspection of the accelerograms. The $\mathrm{IMU}_{\mathrm{MT}}$ was fixed to the MT directly proximal to the stand-alone accelerometer to indirectly synchronize the latter with the cinematographic data. Only data derived from the stand-alone accelerometer at the level of the MT and the $\mathrm{IMU}_{\text {claw }}$ were used for statistical analysis.

Part B of experiment 1 was performed to compare acceleration at the level of the left and right MT. Acceleration was recorded simultaneously with the stand-alone accelerometer and an $\mathrm{IMU}_{\mathrm{MT}}$, one of each attached to each MT. The IMU were again used to synchronize the stand-alone accelerometers with the cinematographic data. The stand-alone accelerometers were used to compare accelerations of $\mathrm{MT}_{\text {right }}$ and $\mathrm{MT}_{\text {left }}$ in groups $\mathrm{C} 1$ and $\mathrm{L} 1$, respectively and to compare the difference between $\mathrm{MT}_{\text {right }}$ and $\mathrm{MT}_{\text {left }}\left(\boldsymbol{\Delta}_{\mathrm{MT}}\right)$ in groups C1 versus L1.

\section{Experiment 2}

For this experiment, only stand-alone accelerometers were used, one of each attached to the left and right MT of each cow. Experiment 2 was performed to compare $\Delta_{\mathrm{MT}}$ in cows of groups C2 versus L2. The result of a thorough orthopedic examination of all 4 feet (presence or absence of foot pathology) was used as the gold standard for group allocation in experiment 2 .

\section{Processing of Accelerometer Data and Identification of Gait Cycle Variables}

A mean of 9 gait cycles (range 4-10) per limb pair was selected by convenience selection from a sample of 3 walking phases (experiment 1) or 1 walking phase (experiment 2) in a straight line after excluding gait cycles representing the cow running or gait cycles with signal artifacts (as determined by visual inspection). The accelerometer data were transformed into a 3-dimensional vector magnitude accelerogram (referred to as a pedogram), represented as

$$
\sqrt{a x^{2}+a y^{2}+a z^{2}}
$$

where $a x, a y$, and $a z$ are the accelerations along the directions of $\mathrm{x}^{-}, \mathrm{y}-$, and $\mathrm{z}$-axis, respectively (Robert et al., 2009; de Passillé et al., 2010).

In experiment 1 , the relevant pedogram variables (analogous to humans) were identified using the cine- 
matographic data by matching each video frame to the corresponding data points (time and peak height), as shown in Figure 1. Definitions of the different cinematographic (phases and peaks) and pedogram variables (complexes, intervals and peaks) are given in Table 1. In experiment 2, the gait initiation and termination complexes as well as the temporal events and peaks of the pedogram were visually identified (Table 1).

\section{Data Analysis and Statistics}

From each gait cycle variable and the time differences of the main peaks between claw and MT, the mean value of the selected gait cycles was calculated for each cow and used for further analysis. In experiment 2 , the variables heel-off and preswing phase were not analyzed, as it was shown in experiment 1 that accurate visual identification in the pedogram (without concurrent use of cinematographic data) was not possible. The differences between the gait cycle variables of the lateral claws and the corresponding MT of group $\mathrm{C} 1$ or between $\mathrm{MT}_{\text {right }}$ and $\mathrm{MT}_{\text {left }}$ of groups $\mathrm{C} 1$ or $\mathrm{C} 2$ were assessed using the paired $t$-test. The stand-alone accelerometers were first used to compare kinematic (temporal) and kinetic (peak) pedogram variables of both hind limbs within cows and groups by subtracting the lower from the higher values

$$
\Delta_{\text {group }}=\sum \frac{\Delta_{\mathrm{MT}}(\text { high }- \text { low })}{n},
$$

where $n=$ number of the cows in the respective group and $\Delta_{\mathrm{MT}}$ for each pedogram variable was calculated as the difference across limbs within cows. Second, these acceleration differences between hind limbs were compared for groups C1 versus L1 ( $\Delta_{\text {nonlame }}$ vs. $\Delta_{\text {lame }}$ ) and $\mathrm{C} 2$ versus L2 $\left(\Delta_{\text {no lesion }}\right.$ vs. $\left.\Delta_{\text {lesion }}\right)$, respectively. The variables of all gait cycles were normally distributed; therefore, $t$-tests were used to compare between groups in both experiments ( $\mathrm{C} 1$ vs. L1 and $\mathrm{C} 2$ vs. L2). A receiver operator characteristic analysis (ROC) was used to determine the performance of the pedogram at the cow level to calculate the optimal cutoff values for the different gait cycle variables (Dohoo et al., 2009). Linear regression was used to determine the association between gait cycle variables and gait score. A Bonferroni corrected $P$-value was calculated to account for multiple comparisons; the significance probability was set at $P \leq 0.05$ (without Bonferroni adjustment). Statistical analyses were undertaken using the software package NCSS $^{10}$ (NCSS, LLC, Kaysville, UT; http:// www.ncss.com/).

\section{RESULTS}

The NRS [means \pm SD (range)] was $1.6 \pm 0.26$ (1.30-2.17) and $3.83 \pm 0.57(3.17-4.67)$ for groups C1 and L1 and $1.68 \pm 0.29(1.17-2.17)$ and $3.24 \pm 0.62$ (1.83-3.83) for groups C2 and L2, respectively. Within each cow, the maximal difference of the NRS among the 3 observers was 0.5 .

\section{Experiment 1}

Part $\boldsymbol{A}$. The pedogram of the lateral claw of group $\mathrm{C} 1$ revealed similarities with the pedogram of the respective MT, but the peaks appeared generally lower and they occurred at the MT with a mean (SEM) delay of 21.43 (1.001) and 11.53 (4.61) ms for foot load and toe-off, respectively, and 14.60 (8.25) ms in advance for heel-off (Figure 1). The foot load peak was higher than the toe-off peak (Table 2), and the gait initiation and the gait termination complexes were divided by a long equilibrium phase with only minor changes in acceleration. The amplitudes of the peaks of foot load, toe-off, and heel-off were higher at the level of the lateral claw as compared with the respective MT (Table 2). Gait cycle duration and the durations of stance and swing phases were not different between claw and MT (Table 2 ), except from the duration of the preswing phase that was significantly higher at the level of the MT as compared with the claw (Table 2).

Part B. In group $\mathrm{C} 1$, the amplitudes of the peaks and the relative temporal events of the gait cycle were not significantly different within pairs of MT, except from the amplitude of the heel-off peak (data not shown). Comparison of $\Delta_{\mathrm{MT}}$ between groups $\mathrm{C} 1$ and L1 showed significantly higher values for all gait cycle variables in group L1 expect from gait cycle duration (Table 2). The optimal cutoff values for identifying the lame cows are shown in (Table 3 ).

\section{Experiment 2}

In group C2, no significant difference between $\mathrm{MT}_{\text {right }}$ and $\mathrm{MT}_{\text {left }}$ was found for any of the gait cycle variables analyzed (data not shown). The mean $\Delta_{\mathrm{MT}}$ of all gait cycle variables analyzed, except from gait cycle duration, was significantly different between groups C2 and L2 (Table 2). The optimal cutoff values for identifying the cows with foot lesion are shown in (Table 3). Linear regression revealed a change of $\Delta_{\mathrm{MT}}$ of stance phase duration, foot load, and toe-off with increasing gait score for group L2 $\left(\mathrm{R}^{2}=0.6\right.$ and slope $=11.7,0.25$ and 2.66, 0.47 and 1.14, respectively) and for group C2 $\left(\mathrm{R}^{2}=0.1\right.$ and slope $=0.6,0.21$ and $-1.05,0.0003$ and 


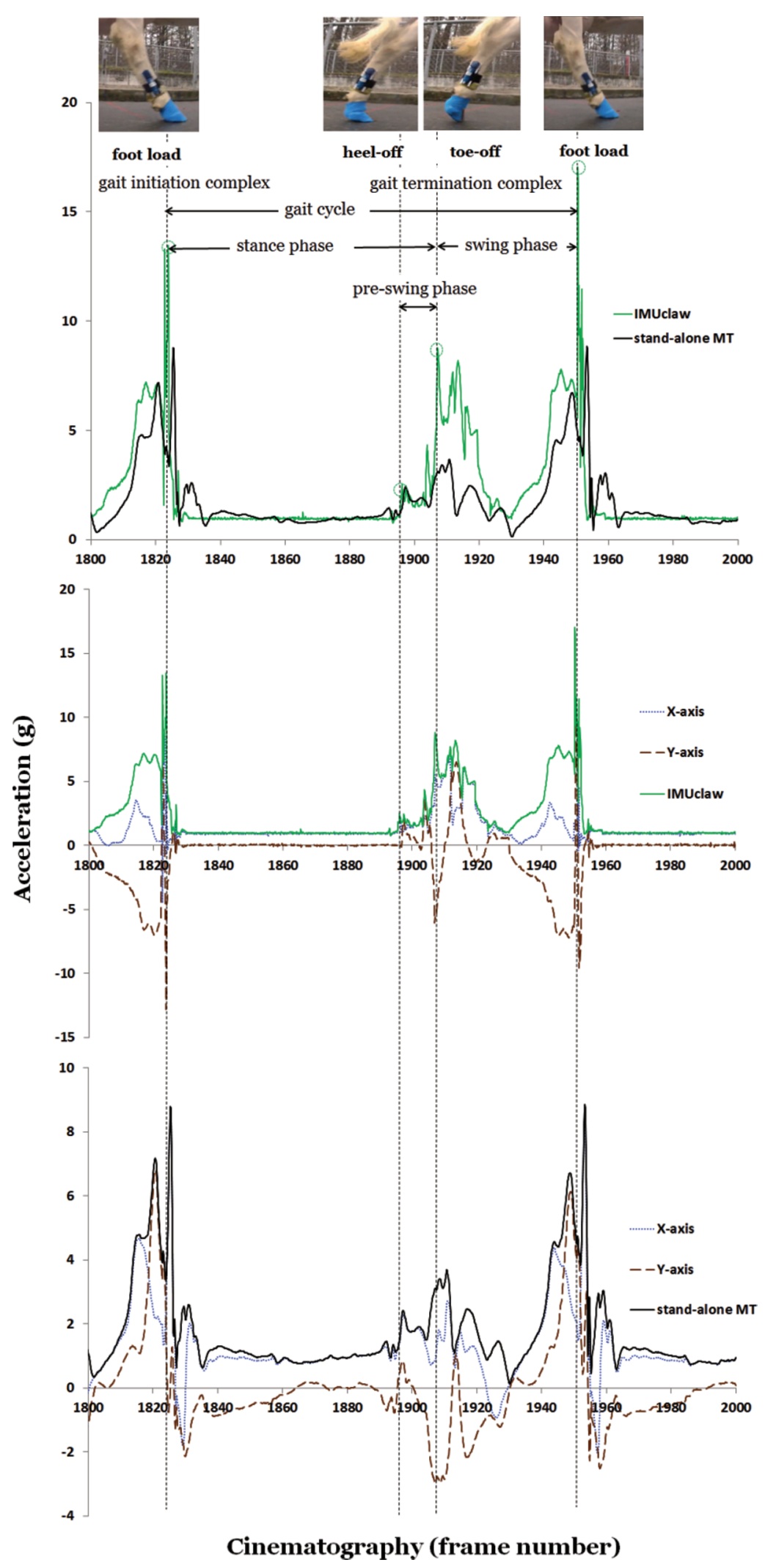

Figure 1. Pedogram with corresponding accelerograms in X- and $\mathrm{Y}$-axes at the levels of claw (IMU $\mathrm{U}_{\text {claw }}$ ) and metatarsus (stand-alone MT) of a nonlame cow (Swiss Fleckvieh, lactation number $=4, \mathrm{BW}=580 \mathrm{~kg}$ ). The circles refer to the maximum peaks of foot load, heel-off, and toe-off of the pedogram at claw level. Color version available online. 
ALSAAOD ET AL.

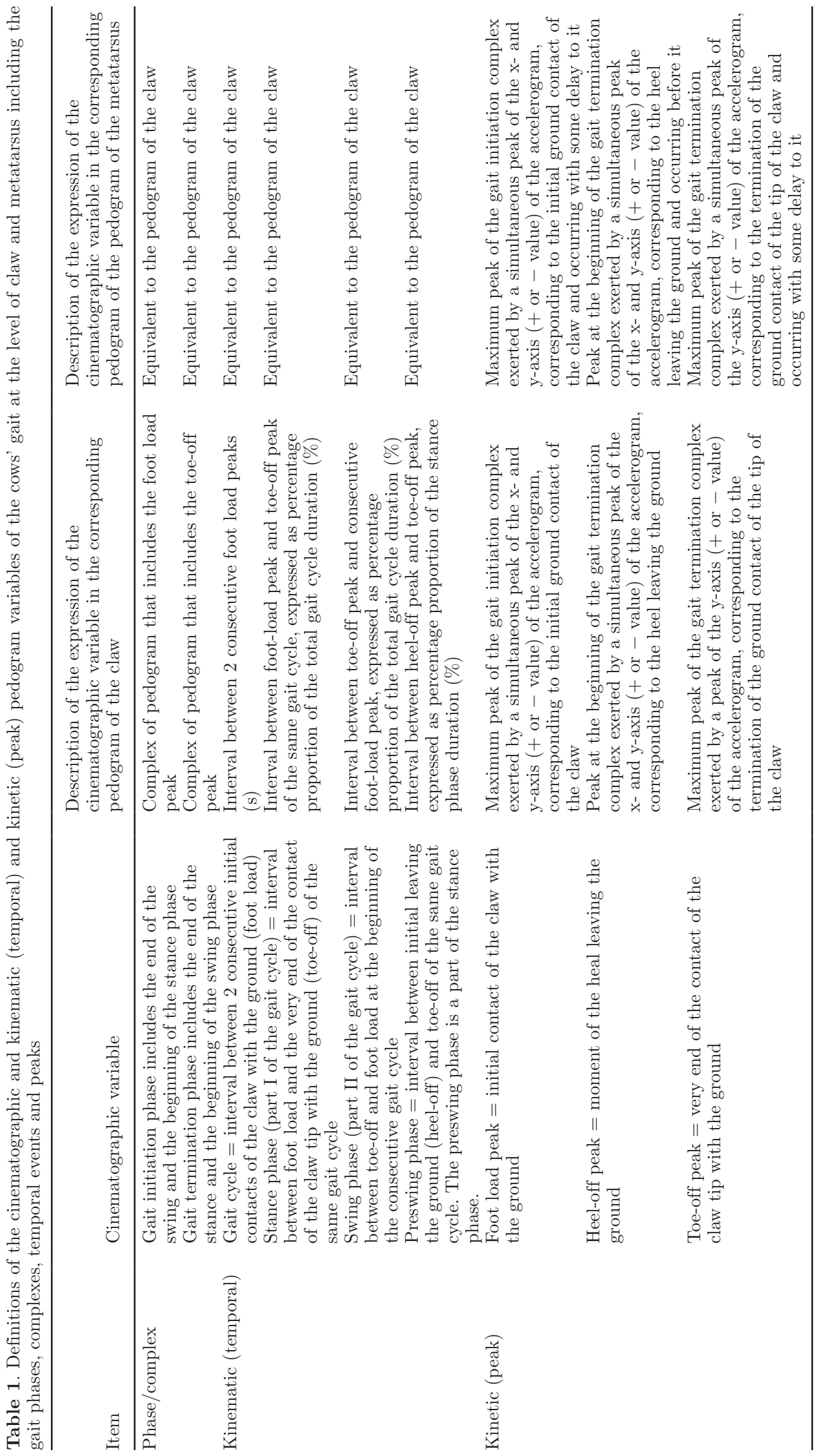



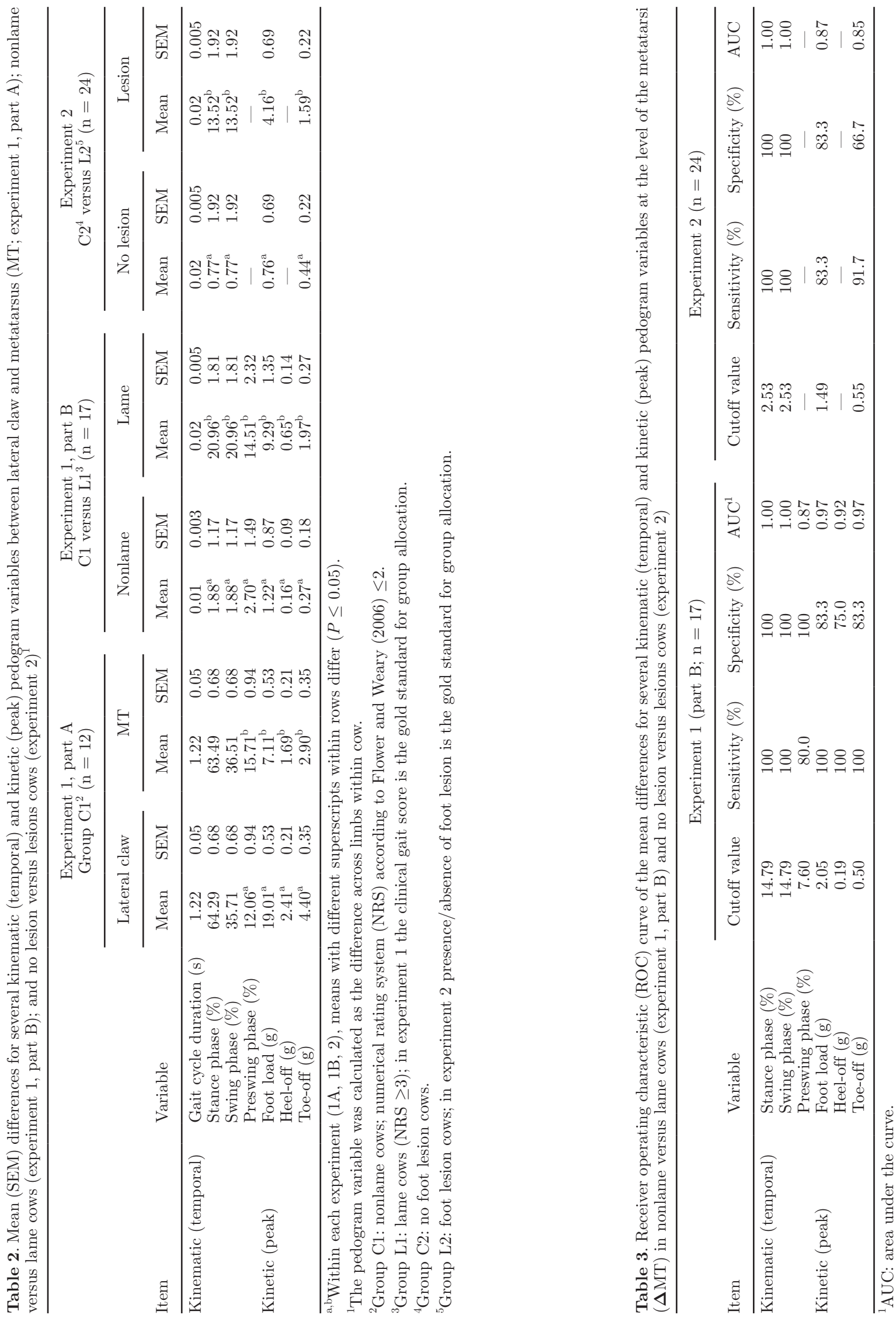
-0.02 , respectively). All lame cows, as well as all cows with foot lesions, in both experiments showed a lower relative stance and higher swing phase duration of the affected limb as compared with the nonaffected limb.

\section{DISCUSSION}

The results of our study show that measuring gait cycle variables at the level of the MT, using stand-alone accelerometers with a high sampling rate $(400 \mathrm{~Hz})$, is adequate to indirectly explore the acceleration of the claw. Simultaneous measurements of gait cycle variables of pairs of MT offer the possibility of differentiating between lame and nonlame cows and between cows with and without unilateral lesions of the hind feet. Using a threshold of $2.53 \%$ for $\Delta_{\mathrm{MT}}$ of stance phase duration, cows with unilateral lesions of the hind feet were detected with a sensitivity and specificity of $100 \%$. To the best of our knowledge, this is the first description of the cow pedogram, further allowing the highly accurate detection of lameness and foot pathologies.

Data of cattle accelerometers and IMU were transformed into a signal vector magnitude (pedogram) to simplify the manual extraction of the essential temporal events and peaks of the gait cycle (Lee et al., 2010) and to compare it to the synchronized cinematographic data. The vector magnitude has the benefit that it represents a robust value, independent of the orientation of the accelerometer, which is arbitrary. The cattle gait cycle consists of 2 main phases, (1) the weight-bearing (stance phase) and (2) the non-weight-bearing (swing phase), as described by Rajkondawar et al. (2006) using a reaction force detection system. Flower et al. (2005) reported that nonlame cows compared with lame cows may have the same absolute duration of temporal events, but may have different relative values, as measured by kinematic techniques. Therefore, the stance, swing, and preswing phases in our study were not considered as absolute values, but rather as the percentage proportions of the total gait cycle or stance phase duration, respectively. Furthermore, to account for individual acceleration differences within cows, data were presented as a difference $\left(\Delta_{\mathrm{MT}}\right)$ between $\mathrm{MT}_{\text {right }}$ and $\mathrm{MT}_{\text {left }}$ in all 4 groups.

Measuring the gait cycle variables at MT is feasible for use in practice. However, measuring the acceleration at the lateral claw with IMU provides information about the contact of the lateral claw with the ground, and its analysis is important to understand the gait cycle variables at the level of the MT. All measurements of claw acceleration were performed at the lateral claw of the hind limbs, as they are exposed to higher pressure while walking on hard surface compared with the medial claw on the same limb (Schmid et al., 2009), and pathologies mainly occur in the lateral hind claws (Murray et al., 1996).

The gait cycle duration was defined as the interval between 2 consecutive foot loads and started with the stance phase. The mean gait cycle duration at MT was estimated at $(1.29 \mathrm{~s})$ and is comparable with previous findings (Flower et al., 2005; Maertens et al., 2011; Van Nuffel et al., 2013; Beer et al., 2016), which defined it as the time interval between 2 consecutive foot imprints of the same foot. As we calculated the $\Delta_{\mathrm{MT}}$ at the cow level, there was no difference in gait cycle duration between the groups of each experiment. Comparing the gait cycle variables of MT and lateral claw in group C1 showed that all the temporal events of the gait cycle were not significantly different, except from the preswing phase, which was significantly longer at MT compared with the lateral claw. Identification of the pre-swing phase at MT was less accurate and less precise as compared with the claw. This may explain why a difference of preswing was found between MT and claw. For this reason, heel-off peak and preswing phase were excluded from further analyses in experiment 2 . The peaks of heel-off, toe-off, and foot load of the lateral claw were significantly higher than those recorded for MT, because the MT is not exposed to such an abrupt change in acceleration.

Reluctance to bear weight on affected limbs can be characterized by reduced limb force (Flower et al., 2005; Rajkondawar et al., 2006; Rushen et al., 2007; Chapinal et al., 2011; Van Nuffel et al., 2013). In our study, the mean $\Delta_{\mathrm{MT}}$ of kinetic variables was significantly higher in the lame group as compared with the nonlame group. In comparison, using a small number of cows, Thorup et al. (2014) investigated the symmetries of left and right limb pair curves using 3-dimensional force plates and showed that lame cows had less symmetry compared with nonlame cows. However, changes of kinetic variables in the vertical axis of cows with similar foot lesions and locomotion score were heterogeneous among cows (Liu et al., 2011). One explanation for this was that cows with painful lateral claws may shift load-bearing to the sound medial claw of the same limb (Dunthorn et al., 2015). Pastell et al. (2009) reported a significant difference in the symmetry of forward acceleration of hind limbs between the gait of lame and sound cows using a wireless 3-dimensional accelerometer system. In our study, all $\Delta_{\mathrm{MT}}$ of kinematic variables of the gait cycle (except gait cycle duration) were significantly different between groups. Similar results were reported by Van Nuffel et al. (2013), showing that lame cows on left hind limbs, as recognized by farmers, had a longer stance time on the contralateral right hind limb compared with nonlame cows as measured by a pressure-sensitive mat. All of these studies also 
provided evidence that lame cows adapted their gait cycle characteristics to minimize the pressure exerted on the affected claw or limb to the healthy contralateral claw or limb to reduce pain.

In experiment 2, we selected the cows based on their foot pathologies, as unilateral hind limb lesions were shown to be the main cause of lameness in dairy cows (Murray et al., 1996). Flower and Weary (2006) reported significant differences of stride variables (length, maximum height, duration of strides, hoof speed, stance, and swing phase duration) between healthy cows and those with sole ulcers at the typical site, but not for cows with sole lesions of other locations, using computer-aided kinematic techniques. They explained this by the high variability among cows concerning sole lesion location, lesion severity, and number of lesions per cow. Chapinal et al. (2011), however, suggested that the asymmetry in variance of acceleration in both pectoral and pelvic limbs was correlated with visual gait scores and asymmetry of the steps in lameness. In our study, we compared the differences of gait cycle variables at cow level and showed that group L2 had significantly higher differences of stance and swing phases and peaks of foot load and toe-off between left and right MT, which was even the case in one cow without any signs of lameness. Tadich et al. (2010) reported that locomotion scoring may not always be sensitive enough to detect foot lesions, and foot lesions can be present without any sign of lameness; thus, lameness does not appear until the lesion is moderate to severe.

In addition, an increase of $\Delta_{\mathrm{MT}}$ of stance phase duration occurred with increasing gait scores, which indicates a decrease in weight-bearing of the affected foot with an increase in the severity of lameness. This is in agreement with the finding of Chapinal et al. (2011), who reported that lame cows with high gait scores have a greater asymmetry of acceleration variance of the front and hind pairs of limbs.

As data of our study were manually extracted, further studies are needed to develop and verify a gait cycle analysis system to automatically extract the various variables of the gait cycle in cattle. An accelerometer with a sample rate of $10 \mathrm{~Hz}$ is more feasible for long-term monitoring the locomotion activity of cows over days or even weeks in dairy farms to detect even slightly lame cows (Beer et al., 2016). The sampling rate of the stand-alone accelerometers of the current study was set at 400 samples per second, representing a very high rate, as compared with previous studies from Pastell et al. (2009; $25 \mathrm{~Hz})$ and Alsaaod et al. (2015; $10 \mathrm{~Hz}$ ), and $400 \mathrm{~Hz}$ is more suitable for precise gait analyses on the individual animal level.

The cow pedogram seems to be a promising tool for detecting lameness and foot pathologies in dairy cows.
Further larger-scale studies are needed to evaluate the sensitivity and specificity across animals with more common and less severe types of limb and foot pathologies.

\section{CONCLUSIONS}

The results of this study show that measuring the acceleration at the level of the MT, using 2 accelerometers with a high sampling rate $(400 \mathrm{~Hz})$ attached to both hind limbs, is a promising tool to indirectly explore the acceleration of the lateral claw and to accurately describe the different gait cycle variables. Furthermore, it represents a unique technique to detect unilateral hind limb lameness and hind limb pathologies in dairy cows with a high accuracy.

\section{ACKNOWLEDGMENTS}

This study was generously supported by grants of the Fondation Sur-La-Croix (Basel, Switzerland).

\section{REFERENCES}

Alsaaod, M., J. J. Niederhauser, G. Beer, N. Zehner, G. SchuepbachRegula, and A. Steiner. 2015. Development and validation of a novel pedometer algorithm to quantify extended characteristics of the locomotor behavior of dairy cows. J. Dairy Sci. 98:6236-6242.

Alsaaod, M., C. Romer, J. Kleinmanns, K. Hendriksen, S. Rose-Meierhofer, L. Plumer, and W. Buscher. 2012. Electronic detection of lameness in dairy cows through measuring pedometric activity and lying behavior. Appl. Anim. Behav. Sci. 142:134-141.

Beer, G., M. Alsaaod, A. Starke, G. Schuepbach-Regula, H. Muller, P. Kohler, and A. Steiner. 2016. Use of extended characteristics of locomotion and feeding behavior for automated identification of lame dairy cows. PLoS One 11:e0155796.

Bicalho, R. C., L. D. Warnick, and C. L. Guard. 2008. Strategies to analyze milk losses caused by diseases with potential incidence throughout the lactation: a lameness example. J. Dairy Sci. 91:2653-2661.

Chapinal, N., A. M. de Passille, M. Pastell, L. Hanninen, L. Munksgaard, and J. Rushen. 2011. Measurement of acceleration while walking as an automated method for gait assessment in dairy cattle. J. Dairy Sci. 94:2895-2901.

de Passillé, A. M., M. B. Jensen, N. Chapinal, and J. Rushen. 2010. Technical note: Use of accelerometers to describe gait patterns in dairy calves. J. Dairy Sci. 93:3287-3293.

Dirksen, G., H.-D. Gründer, and M. Stöber. 2012. Die Klinische Untersuchung des Rindes. 4th ed. Enke Verlag, Stuttgart, Germany.

Dohoo, I., W. Martin, and H. Stryhn. 2009. Veterinary Epidemiologic Research. VER Inc., Charlottestown, PEI, Canada.

Dunthorn, J., R. M. Dyer, N. K. Neerchal, J. S. McHenry, P. G. Rajkondawar, G. Steingraber, and U. Tasch. 2015. Predictive models of lameness in dairy cows achieve high sensitivity and specificity with force measurements in three dimensions. J. Dairy Res. 82:391-399.

Engel, B., G. Bruin, G. Andre, and W. Buist. 2003. Assessment of observer performance in a subjective scoring system: Visual classification of the locomotion of cows. J. Agric. Sci. 140:317-333.

Flower, F. C., D. J. Sanderson, and D. M. Weary. 2005. Hoof pathologies influence kinematic measures of dairy cow gait. J. Dairy Sci. 88:3166-3173.

Flower, F. C., and D. M. Weary. 2006. Effect of hoof pathologies on subjective assessments of dairy cow gait. J. Dairy Sci. 89:139-146. 
Holzhauer, M., H. Middelesch, C. J. M. Bartels, K. Frankena, E. N. Verhoeff, E. N. Noordhuizen-Stassen, and J. P. T. M. Noordhuizen. 2005. Assessing the repeatability and reproducibility of the leg score: A Dutch claw health scoring system for dairy cattle. Tijdschr. Diergeneeskd. 130:440-443.

Huxley, J. N. 2012. Lameness in cattle: An ongoing concern. Vet. J. 193:610-611.

Leach, K. A., D. A. Tisdall, N. J. Bell, D. C. J. Main, and L. E. Green. 2012. The effects of early treatment for hindlimb lameness in dairy cows on four commercial UK farms. Vet. J. 193:626-632.

Lee, J. A., S. H. Cho, Y. J. Lee, H. K. Yang, and J. W. Lee. 2010 Portable activity monitoring system for temporal parameters of gait cycles. J. Med. Syst. 34:959-966.

Liu, J., R. M. Dyer, N. K. Neerchal, U. Tasch, and P. G. Rajkondawar. 2011. Diversity in the magnitude of hind limb unloading occurs with similar forms of lameness in dairy cows. J. Dairy Res. 78:168177 .

Lugade, V., V. Lin, A. Farley, and L. S. Chou. 2014. An artificial neural network estimation of gait balance control in the elderly using clinical evaluations. PLoS One 9:e97595.

Maertens, W., J. Vangeyte, J. Baert, A. Jantuan, K. C. Mertens, S. De Campeneere, A. Pluk, G. Opsomer, S. Van Weyenberg, and A. Van Nuffel. 2011. Development of a real time cow gait tracking and analysing tool to assess lameness using a pressure sensitive walkway: The GAITWISE system. Biosyst. Eng. 110:29-39.

Mariani, B., H. Rouhani, X. Crevoisier, and K. Aminian. 2013. Quantitative estimation of foot-flat and stance phase of gait using footworn inertial sensors. Gait Posture 37:229-234.

Murray, R. D., D. Y. Downham, M. J. Clarkson, W. B. Faull, J. W. Hughes, F. J. Manson, J. B. Merritt, W. B. Russell, J. E. Sutherst, and W. R. Ward. 1996. Epidemiology of lameness in dairy cattle: Description and analysis of foot lesions. Vet. Rec. 138:586-591.

Nechanitzky, K., A. Starke, B. Vidondo, H. Muller, M. Reckardt, K. Friedli, and A. Steiner. 2016. Analysis of behavioral changes in dairy cows associated with claw horn lesions. J. Dairy Sci. 99:2904-2914.

Olsen, E., P. H. Andersen, and T. Pfau. 2012. Accuracy and precision of equine gait event detection during walking with limb and trunk mounted inertial sensors. Sensors (Basel) 12:8145-8156.

Pastell, M., J. Tiusanen, M. Hakojarvi, and L. Hanninen. 2009. A wireless accelerometer system with wavelet analysis for assessing lameness in cattle. Biosyst. Eng. 104:545-551.

Poursaberi, A., C. Bahr, A. Pluk, A. Van Nuffel, and D. Berckmans, 2010. Real-time automatic lameness detection based on back posture extraction in dairy cattle: Shape analysis of cow with image processing techniques. Comp. Elec. Agric. 74:110-119. https://doi. org/10.1016/j.compag.2010.07.004

Rajkondawar, P. G., M. Liu, R. M. Dyer, N. K. Neerchal, U. Tasch, A. M. Lefcourt, B. Erez, and M. A. Varner. 2006. Comparison of models to identify lame cows based on gait and lesion scores, and limb movement variables. J. Dairy Sci. 89:4267-4275.

Robert, B., B. J. White, D. G. Renter, and R. L. Larson. 2009. Evaluation of three-dimensional accelerometers to monitor and classify behavior patterns in cattle. Comput. Electron. Agric. 67:80-84.
Rushen, J., E. Pombourcq, and A. M. de Passillé. 2007. Validation of two measures of lameness in dairy cows. Appl. Anim. Behav. Sci. 106:173-177.

Schlageter-Tello, A., E. A. M. Bokkers, P. W. G. G. Koerkamp, T. Van Hertem, S. Viazzi, C. E. B. Romanini, I. Halachmi, C. Bahr, D. Berckmans, and K. Lokhorst. 2015. Relation between observed locomotion traits and locomotion score in dairy cows. J. Dairy Sci. 98:8623-8633.

Schmid, T., M. A. Weishaupt, S. W. Meyer, N. Waldern, K. Peinen, and K. Nuss. 2009. High-speed cinematographic evaluation of clawground contact pattern of lactating cows. Vet. J. 181:151-157.

Shearer, J. K., M. L. Stock, S. R. Van Amstel, and J. F. Coetzee. 2013. Assessment and management of pain associated with lameness in cattle. Vet. Clin. North Am. Food Anim. Pract. 29:135-156.

Sprecher, D. J., D. E. Hostetler, and J. B. Kaneene. 1997. A lameness scoring system that uses posture and gait to predict dairy cattle reproductive performance. Theriogenology 47:1179-1187.

Tadich, N., E. Flor, and L. Green. 2010. Associations between hoof lesions and locomotion score in 1098 unsound dairy cows. Vet. J. 184:60-65.

Thomas, H. J., J. G. Remnant, N. J. Bollard, A. Burrows, H. R. Whay, N. J. Bell, C. Mason, and J. N. Huxley. 2016. Recovery of chronically lame dairy cows following treatment for claw horn lesions: A randomised controlled trial. Vet. Rec. 178:116.

Thorup, V. M., O. F. do Nascimento, F. Skjoth, M. Voigt, M. D Rasmussen, T. W. Bennedsgaard, and K. L. Ingvartsen. 2014 Changes in gait symmetry in healthy and lame dairy cows based on 3-dimensional ground reaction force curves following claw trimming. J. Dairy Sci. 97:7679-7684.

Van Hertem, T., S. Viazzi, M. Steensels, E. Maltz, A. Antler, V. Alchanatis, A. A. Schlageter-Tello, K. Lokhorst, E. C. B. Romanini, C. Bahr, D. Berckmans, and I. Halachmi. 2014. Automatic lameness detection based on consecutive 3D-video recordings. Biosyst. Eng. 119:108-116.

Van Nuffel, A., M. Sprenger, F. A. M. Tuyttens, and W. Maertens 2009. Cow gait scores and kinematic gait data: Can people see gait irregularities? Anim. Welf. 18:433-439.

Van Nuffel, A., J. Vangeyte, K. C. Mertens, L. Pluym, S. De Campeneere, W. Saeys, and S. Van Weyenberg. 2013. Exploration of measurement variation of gait variables for early lameness detection in cattle using the GAITWISE. Livest. Sci. 156:88-95.

Viazzi, S., C. Bahr, A. Schlageter-Tello, T. Van Hertem, C. E. B. Romanini, A. Pluk, I. Halachmi, C. Lokhorst, and D. Berckmans. 2013. Analysis of individual classification of lameness using automatic measurement of back posture in dairy cattle. J. Dairy Sci. $96: 257-266$

Walker, A. M., T. Pfau, A. Channon, and A. Wilson. 2010. Assessment of dairy cow locomotion in a commercial farm setting: The effects of walking speed on ground reaction forces and temporal and linear stride characteristics. Res. Vet. Sci. 88:179-187. 